\title{
Development (and Evolution) of the Universe
}

\section{Foundations of Science}

The official Journal of the Association for Foundations of Science, Language and Cognition

\section{ISSN 1233-1821}

Volume 15

Number 4

Found Sci (2010) 15:357-367

DOI 10.1007/s10699-010-9181-

z

\section{FOUNDATIONS}

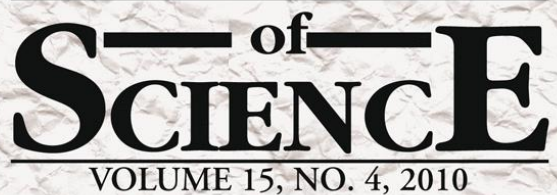

Special Issue Section

Evolution and Development of the Universe, Part III Philosophy and Big Questions

Guest Editor Clément Vidal 
Your article is protected by copyright and all rights are held exclusively by Springer Science+Business Media B.V.. This e-offprint is for personal use only and shall not be selfarchived in electronic repositories. If you wish to self-archive your work, please use the accepted author's version for posting to your own website or your institution's repository. You may further deposit the accepted author's version on a funder's repository at a funder's request, provided it is not made publicly available until 12 months after publication. 


\title{
Development (and Evolution) of the Universe
}

\author{
Stanley N. Salthe
}

Published online: 9 June 2010

(C) Springer Science+Business Media B.V. 2010

\begin{abstract}
I distinguish Nature from the World. I also distinguish development from evolution. Development is progressive change and can be modeled as part of Nature, using a specification hierarchy. I have proposed a 'canonical developmental trajectory' of dissipative structures with the stages defined thermodynamically and informationally. I consider some thermodynamic aspects of the Big Bang, leading to a proposal for reviving final cause. This model imposes a 'hylozooic' kind of interpretation upon Nature, as all emergent features at higher levels would have been vaguely and episodically present primitively in the lower integrative levels, and were stabilized materially with the developmental emergence of new levels. The specification hierarchy's form is that of a tree, with its trunk in its lowest level, and so this hierarchy is appropriate for modeling an expanding system like the Universe. It is consistent with this model of differentiation during Big Bang development to view emerging branch tips as having been entrained by multiple finalities because of the top-down integration of the various levels of organization by the higher levels.
\end{abstract}

Keywords Big Bang · Causality · Development · Multiple worlds · Nature · Specification hierarchy $\cdot$ Thermodynamics $\cdot$ Vagueness

\section{Introduction}

In this paper I attempt a summary of a developmental perspective I have been constructing for two decades as a kind of 'treaty' among several disciplines. Beginning with some conceptual clarifications, I distinguish 'Nature', our scientific construct, from the World. Nature is our

S. N. Salthe $(\bowtie)$

Biological Sciences, Binghamton University, 42 Laurel Bank Avenue, Deposit, New York 13754, USA e-mail: ssalthe@binghamton.edu

S. N. Salthe

Emeritus, Biology, City University of New York, 42 Laurel Bank Avenue, Deposit, New York 13754, USA 
map or operating manual for the World. Nature embodies logic as its basic framework, and its embodiments are typically found in, e.g., inscriptions, diagrams, tables, models, equations, laws, universal constants and classifications. Nature is the subject of studies in the philosophy of nature (natural philosophy), as in this paper. It is mediated by languages, while the World is mediated to us through (what in Nature we know as) our biology (Uexküll 1926). The World is experienced and phenomenal, but is not 'known' (Snowdon 2008). My favorite example of this is that, while we may ride a bicycle, we do not 'know' (cannot describe) how we do it. I will as well propose a logically founded model in set theory format of 'general development', which is posited to be universal for dissipative structures as they are conceived in Nature. Of course, set theory cannot model dynamical change. I use this format to parse sequences of developmental stages, following the usage (as Normentafeln) in biology. I will also, in this way of describing stages of development, outline a 'canonical developmental trajectory' characteristic of dissipative structures. I acknowledge evolution in passing. As a cue to the reader, I note that my perspective is that of natural philosophy as developed out of beginnings made by the early Friedrich Wilhelm Joseph Schelling (e.g., Esposito 1977; Salthe 1993). What is relevant here is that Schelling first proposed a developmental view of the natural world.

\section{Modes of Change}

Generalized from their long usage in biology, I distinguish development from evolution, as general modes of change (Salthe 1993). Development is progressive change, while evolution is expressed in the effects of accumulating marks acquired from contingent encounters. Developments, interpreted as constitutive of the kinds of systems showing them, can be modeled as parts of Nature. Well known examples that I would place as developments are the 'main sequence' of stars, embryonic development, and ecological succession. Developments are like Goodman's (1976) 'scripts', but inferred from scientific investigations rather than by creative action. Evolution (more generally, individuation) occurs continually during the development of any material system, building in historically acquired information, leading to increasing dimensions of uniqueness in particular phenomena. One very important kind of particular phenomenon in science is the biological species. A species' storage of historically acquired information is held in the genomes of the cells of its parts, as well as in material configurations in cell structures. At its own scale each species is unique; while at their scales, its parts (e.g., organisms) differentiate increasingly as they recover from perturbations during development, becoming ever more intensively unique.

With regard to evolution, given the need perceived in Nature for systemic mutual fittingness, some phenomena will inevitably not be as well suited to persist in their surroundings as others, and these get recycled more rapidly than those more 'fitting' or 'better adapted'. This fact of differential persistence has been elaborately constructed as competition in our Western cultural ideology, and is highly developed in neoDarwinian evolutionary biology, where it plays out as competition between genotypes for representation in future generations of a population (e.g., Ewens 2004). But this is a small aspect of the 'big picture' of change in Nature. A simplest kind of example of selection would be the self-organizing choice of a drainage channel from among several possibilities by a high altitude water reservoir as it develops from glacier to lake (Salthe and Fuhrman 2005). All actual phenomena have been individuated by evolution. This paper, however, is concerned with development. 


\section{Development}

Development proceeds from relatively vague beginnings toward ever more specified particulars. It is logically a process of refinement via the differential promotion of potential informational constraints, followed by the subsequent fixation of some of them. Informational constraints are sites or regions that might assume more than one configuration. After choosing among possibilities, they express information. As development continues, an early informational constraint can become the site for the emergence of others. Stages of development can be conveniently represented using set theoretic format, as:

\section{\{stage 1 stage 2 stage 3$\}\}$ \}}

Stage 2 develops out of Stage 1, and Stage 3 from Stage 2. Stage 2 is necessarily immanent, along with other possibilities, in Stage 1. More developed stages are in this model logically refinements of earlier stages, by way of having acquired further information. That is, an early stage anlagen will be only roughly_vaguely_adumbrated. It will be preserved in development, but increasingly altered downstream in a way that would require more information to describe.

Guidance by this hierarchical format (see details below) imposes a certain logical structure upon development which helps to guide our thinking about it. An important example of this guidance is the stricture that nothing totally new appears during development; instead some of the vague tendencies in a given stage become ever more definitely embodied in further stages, emerging ever more definitively. This perspective runs counter to the currently favored perspective that genuinely new things do appear in the world. Novelty in the present view can be initiated by way of perturbations from outside, or by internal excursions, during a developing system's individuation. These may become integrated into an emerging system during its development and homeostasis. For example, in the development of an organism, congenital perturbations of an embryo can result in abnormalities that become smoothly integrated into the living individual (Reid 2007). These individuating modifications of a developmental trajectory are almost always of minor import compared with typical developmental patterns. When they are more important, the developing system is likely to fail. Historical impacts always do frequently perturb a surviving developing system to some, relatively minor, degree.

The imposition of this model upon development, including its broader application to the development of the universe, is a major departure of this paper. The logic is developed thus: the quintessential example of development can be found in embryonic development. What I have said above can be derived from observing this particular case. The extension of this model to dissipative structures in general is effected by looking for more generally applicable descriptors, like thermodynamic and information theoretic ones. There are few developmental tendencies that can be said to be universal. As an example, I have proposed (Salthe 1993) a 'canonical developmental trajectory' of dissipative structures running from immaturity through maturity (in more well integrated systems) to senescence, with these stages defined thermodynamically and Informationally, as shown in Table 1. Extension further to the universe as a whole is of course speculative, but is encouraged by the developmental sequences of, for example, stars (e.g., Chaisson 2001).

A developing system builds in informational constraints, and fixes many of them in the manifest information of definite form, upon which further constraints may emerge (Brooks and Wiley 1988). Abiotic developments (as in tornadoes) never get to be very highly specified; internally stored informational constraints, such as are held in the genetic apparatus of living systems, is required for that. I would suggest that, if we propose a system that does not develop from immaturity to senescence, that this would not be a bonafide material system, 
Table 1 Thermodynamic and informational criteria of the developmental stages of dissipative structures. See Salthe $(1989,1993)$ for more details and citations

\author{
IMMATURE STAGE \\ Relatively high energy density (per unit mass) flow rate \\ Relatively small size and/or gross mattergy throughput \\ Rate of acquisition of informational constraints relatively high, along with high growth rate \\ Internal stability relatively low (it is changing fast), but dynamical stability (persistence) is high \\ Homeorhetic stability to same-scale perturbations relatively high \\ MATURE STAGE (only in relatively very stable systems) \\ Declining energy density flow rate is still sufficient for recovery from perturbations \\ Size and gross throughput is typical for the kind of system \\ Form is definitive for the kind of system \\ Internal stability adequate for system persistence \\ Homeostatic stability to same-scale perturbations adequate for recovery \\ SENESCENT STAGE \\ Energy density flow rate gradually dropping below functional requirements \\ Gross mattergy throughput high but its increase is decelerating \\ Form increasingly accumulates deforming marks as a result of encounters, as part of individuation \\ Internal stability of system becoming high to the point of inflexibility \\ Homeostatic stability to same-scale perturbations declining
}

but possibly part of one instead. Thus, for example, the biological population might better be viewed as part of an ecosystem (Damuth 1985), where development has been successfully proposed as the process of ecological succession (Holling, e.g., 1986; Ulanowicz, e.g., 1997). The same may be said of the biological species (Simpson 1953), except that the larger scale material dissipative structure that it would be part of has not, I think, yet been identified, since a species' areographic extent, or the migrations of its parts, could place it as a component of more than one biome.

\title{
4 Development of the Universe
}

I make a materialist interpretation of the Big Bang theory (e.g., Chaisson 2001; Turner 2007; Lineweaver and Egan 2008). Accelerated Universal expansion of space leads to the precipitation of matter, which initiates gravitation and the clumping of masses. Based on Einstein's physical intuition that led to the 'equivalence principle' (Einstein 1907), gravitation can be postulated to be a kind of obverse of accelerated expansion, leaving matter 'behind' as spacetime expands. Acceleration is required here in order to understand why matter was unable to stay in equilibrium with expanding space (Nicolis 1986). Assuming that the universe is a thermodynamically isolated system, my own further interpretation follows. The process of expansion continues to produce an increasingly disequilibrated universe, wherein develop, from the masses in some locales, forms, and from the forms in yet fewer places, organizations, moving the Universe ever further from thermodynamic equilibrium. I conjecture that continued development of increasingly complicated systems depends upon the continuation of Universal expansion. In an 'equal and opposite' reaction to these disequilibrating processes, the Second Law of thermodynamics emerges globally, scaled to the rate of Universal 
expansion. At present this imposes locally the necessity for significant entropy production in connection with any energy dissipation (Prigogine 1955). Consequently, when dissipation is harnessed to effective work, that work is rarely better than around $50 \%$ energy efficient (Odum 1983; Turner 2000). Urgency, striving and haste make work even less energy efficient (Carnot 1824). These facts can lead to a resuscitation of final cause in physics since entropy production is the way that non-equilibrium locales can promote Universal thermodynamic equilibration.

\subsection{Causality}

I have proposed reviving the Aristotelian causal analysis (e.g., Matthen 1989) as being helpful for dealing with complex systems (e.g., Salthe 1985, 1993; Salthe and Fuhrman 2005). Complexity involves a number of factors, including local interactions and transactions of numerous differently capable elements of varying kind and scale as components of a system (e.g., Salthe 2006b), as well as historicity and vagueness. The Aristotelian causal categories help somewhat to tease apart some of this complexity by allocating different modes of causation. In my analysis (2006a), material cause is susceptibility; formal cause is the 'set-up'. Susceptibility refers to the readiness of a locale or a material to undergo the kind of change being modeled, while the set-up refers to the organization of initial and boundary conditions impinging upon that locale or material. Together these synchronic categories establish the locale of relevant or investigated events, as well as the propensities (Popper 1990) of occurrences of various events. Efficient cause is a forcing or push, getting the change going; final cause is the pull of 'why' anything happens. A lightning strike makes a convenient example, with a local buildup of electrical energy gradient as charge separation between clouds or between clouds and the ground, based on the formal cause of large scale local dynamical and structural configurations, with the push given by some perturbation after the system has reached a threshold of instability, and with finality found in the pull of the Second Law of thermodynamics (again, assuming that the universe is a thermodynamically isolated system).

Of course, finality has been banished from natural science for some centuries now (e.g., Weber 1908), largely I believe because of that discourse's entrainment by pragmatic applications, where human intentionality trumps other possible entrainments. To enforce this interdiction, finality has usually been said to imply forbidden religious connotations. The science informed by this opinion was/is a science of conceptually simple, if technically complicated, experimental constructions. These are focused upon setting up formal arrangements that could produce desired kinds of results when initiated by an experimenter's - or some 'natural' - forcing. But now that we are becoming buried in complexity, we may need any tool we can find. Ecologists have already begun tentatively using these causal categories (e.g., Patten et al. 1976; Ulanowicz 1997). Computer simulations would be an ideal medium for exploring the relations between the Aristotelian causal categories in various applications.

I use final causation in order to explain a major factor in our lives and economy-the relatively poor energy efficiency of effective work-otherwise left unexplained as to 'why' it must be the case. To understand this one needs to understand that the Second Law of thermodynamics is a final cause of all events and occasions insofar as they are mediated by energy flows. Whatever happens, including work, happens as an aspect of the dissipation of metastable energy gradients (e.g., Schneider and Kay 1994) in a universe far from thermodynamic equilibrium. Work is linked to this dissipation of energy gradients, and mediates some relatively small portion of that energy (the 'exergy') into action and/or products of lesser energy amount than that dissipated from the tapped gradients. Because the energy efficiency 
of work is so poor, it is possible to see that any work is undertaken in order to move the universe closer to thermodynamic equilibrium. If work efficiency could be much greater, this view would be untenable. Since it cannot (Odum 1983), this understanding seems obligatory, even if not fully explanatory regarding any given work done, which would be associated with various biological, personal and sociocultural finalities. I feel that denying this surprising view would be tantamount to claiming omniscience - that is to say, claiming to know of a counter example hidden away in some obscure corner of the universe. In order to explore this further I will parse finality throughout Nature, for which I need to use a hierarchy format.

\subsection{Synoptic View of Embodiment within Universal Development}

I use the Specification Hierarchy format (Salthe 1993, 2002, 2006b) to make a fully global representation of any unique particular. For example:

\section{\{physical dynamics \{material connectivities \{biological activities \\ \{individual action $\{$ sociopolitical projects $\}\}\}\}$ \}}

with \{lower level \{higher level\}\} and \{more generally distributed \{more particular\}\}; the brackets have the same meaning as in set theory

Thus:

\{dissipative structure \{living system \{animal \{human $\{$ myself $\}\}\}\}$ \}

(I do not here distinguish natural kinds from individuals, as natural kinds are categories resulting from unrelated analysis)

The levels here are 'integrative levels' (Salthe 1988), or ontological levels (Poli 1998). They have been constructed during the progress of Western science, as the subjects of different investigations. As noted already in the 'unity of the sciences' perspective (Neurath et al. 1955-1969) lower levels give rise to and subsume all higher ones, but as well, we now realize that higher ones integrate and harness all lower ones under their own rules locally. Thus, consider:

\section{\{entropy production $\{$ free energy decline $\{$ work $\}\}\}$}

Here each level entrains at least one finality, with lower level, physical, finalities present as relatively weak entrainments locally compared to higher-level ones. But they are continuously in place, whereas higher level entrainments are episodic, and different ones may cancel each other out. As an example of the pervasiveness of the Second Law in our own lives, we might note our tendency to fidget in many ways when more important work is not at hand. Thus, activity of any kind in the non-equilibrium situation is (whatever else of greater import to us it might be) a local contribution to Second Law finality-in the service of the equilibration of our thermodynamically isolated, currently disequilibrated Universe.

As I mentioned earlier, another aspect of this hierarchical model is that it can have a diachronic interpretation as development (Salthe 1993). This is based on the fact that higher levels are logically refinements of lower level possibilities, with the general developmental process then being:

\{vaguer $->$ \{more definite $->$ \{more mechanistic $\}$ \} (the arrows representing change)

For the earth, this could be represented as (Vernadsky 1944, 1986)

$$
\text { \{geosphere }->\text { biosphere }->\text { \{noosphere }\}\}
$$


In application to the Universe, this pattern would proceed at different rates in the different ontological levels. Thus, the material/chemical level would have reached a mechanistic stage with the establishment of the relations shown in the Periodic Table, while the biological level did not reach that stage until much later, with the genetic code and associated apparatus. Continuing this trend, some believe that we are engaged in constructing a noosphere, which would be the mechanization of human culture.

One way of imagining this developmental process is to focus on the lowest physical level, the quark-gluon plasma. In the early universe there would have been a virtually unlimited number of degrees of freedom for any particle in regard to its position and momentum. After the origin of atoms, many degrees of freedom for many of these particles would have become frozen out. With the further emergence of molecules, the degrees of freedom of these same fundamental particles would have become even further restricted, and so on (Salthe 2009).

This model imposes a 'hylozooic' kind of interpretation upon Nature, somewhat like that of Charles Peirce (1938-1951, CP 6.32-6.33). Nothing totally new can appear after the initial expansion of the primal singularity. And so all emergent features that appear later at higher integrative levels would have been implicit during earlier developmental stages. One could say that these later emergents are somewhat like the 'high grade actual occasions' of Whitehead (1929), precipitating within the local society of 'actual occasions', thereby pointing to another 'take' on development as here understood. In this view the past is present in any current individual or occasion. In the present interpretation, these would initially have been only vaguely and episodically present as sketched in the lower integrative levels, but would have become stabilized materially with the developmental emergence of higher integrative levels. This would have occurred globally during development of the earth, but is also repeated locally during the development of, e.g., a living thing like myself. In this development, particles that had become 'captured' by atoms, became / become further restricted in their motions when these atoms are incorporated into molecules which are parts of cells, most of whose physical degrees of freedom are almost reduced to nothing within an organism. Their 'universal' degrees of freedom have then become restricted to being consequences of organismic motion (if any).

Thus, the configuration of fundamental particles within my body at this moment will have occurred transiently many times in the primal quark-gluon plasma after it had reached a certain volume. More colorfully, I will have had a 'ghostly' presence almost since the beginning of the universe, and have been 'lucky' to have become embodied at last! There is thus, in this sense, 'nothing new under the sun', but some things have become increasingly more definite as the universe continued to expand. This is a weakly deterministic philosophical position. On the one hand, our 'ghostly' representation in the quark-gluon plasma will have been unstable, episodic, and without the higher level details that would need to be acquired through historical adventures as the universe developed. On the other hand, those historical adventures might have eliminated the possibility of continued materialization of any particulate lower level template. Thus, while nothing completely new-i.e., not fostered by an ancestral particulate template-can appear, not all such potential templates get to be fostered by any given unfolding history.

Some will argue that a new species of sparrow, a new crime, or a new poem are examples of genuine newness. Note that I hold that all possibilities for any potential universal development to have been present in vague form initially, and that only some get to become more definite during universal development. This 'becoming more definite' involves what many take to be genuinely new things. Each new species or poem may seem 'new' before our eyes, but this level of newness is trivial in the universal-and in the developmental-perspective. 
Each is developmentally a restriction on what was possible before that emergence. Consider language. Having chosen English we can say an unlimited number of things, but we cannot express certain larger moods accessible, say, in French (Salthe 2000) and which may have been conveyable in the ancestral common language.

The above perspective can be played off against the idea emphasizing that every actual occasion would be unique in the higher integrative levels, signaling a radical indeterminacy in the world (Elsasser 1969; Ulanowicz 2007). Anticipating the future, as in the predictive mode of science, there would seem to be an immense number of different higher level configurations potentially emergent at any future locale in a future moment. Thus, whatever happens at these higher integrative levels (biological, sociocultural) would be something completely new, and emergent at these levels. But at the lower, physico-chemical levels, any configuration whatever will have been rehearsed many times. Looking the other way, back from what has occurred, historicity, even at the higher levels, will have narrowed the possibilities gradually, by way of concatenated contingencies as the present moment was unfolding. Whatever actually occurs will have been prefigured at the lower integrative levels and gradually prepared for at the higher levels. Present configurations at the higher integrative levels therefore imply - that is, material implication or conceptual subordination - that which gave rise to them. This looking backward (note also the 'anthropic principle', whether 'strong' or 'weak') is a mode of finality, and narrates how I, the current observer, came to be here in this world.

\subsection{The Logic of Multiple Worlds}

Multiple worlds are implicit in the specification hierarchy model because its form is that of a tree, with its trunk in its lowest level - in the present application that would be the physical integrative level. Inasmuch as I am here assuming that this refers to our known physics, I am not appealing here to particular models of 'multiple universes' imagined by some cosmologists. A subsumptive hierarchy is plainly appropriate for modeling an expanding system like the Universe, which, in the developmental model used here, then can become occupied by ever more, ever more definite, locales. Even if no new matter continues to appear in the expanding universe, the continual incorporation of historical information at every gravitating material locale would result in the emergence of increasingly more individuated phenomena. Every emerging locale acquires its own unique configurations and conformational possibilities. Shown in the hierarchies above are only single branches of this hierarchy, where the lower levels would be shared by increasingly more possible branch tips that are not being represented. Thus. e.g., there could logically be some other kinds of dissipative structures coordinate with living ones. These would not be abiotic ones like eddies and tornadoes because those represent the grounds from which living dissipative structures emerged, and so they are relatively lower level, and therefore not coordinate with the living. Other possibilities would also not be mechanical ones like automated factories, because these are fostered by socioeconomic systems and so are relatively higher level to, and so again not coordinate with, the living.

It seems most likely that in any given world only a few of the immense number of vague tendencies in the primal quark-gluon plasma would get to become stabilized in that world. This would be especially true of those entrained into the highly individuated systems emergent in the highest integrative levels. It would be consistent with this model of differentiation during the development of the Big Bang to view emerging branch tips in the hierarchy as 
having been entrained by multiple finalities. That is, we might reasonably consider every actual occasion to be the locus of several finalities.

\subsection{Integration}

I think it important to end this essay by emphasizing the top-down integration of the various levels of organization (e.g., Greenberg and Tobach 1988) in the specification hierarchy model. This aspect is perhaps the major message, as yet little noted, from the continuing development of the unity of the sciences perspective. On the template of:

\{physical universe\{material locales \{biological forms \{sociocultural organizations\}\}\}\}

We can consider the relations among:

\{dynamics $\{$ location $\{$ form $\{$ functional individuality\}\}\}\}

Consider the interpenetration of these levels in any high enough grade of actual occasion. There can be no activity at any level that is not actually physical dynamics fostered by entropy production. And there can be no location that is not mediated by gravitating matter and chemical affordances. As well, all human inventions are 'inhabited' by the human form, as, e.g., a pile driver represents the human arm. For a currently actively pursued example, biological form and function is largely constrained by scale (Bonner 2006; Brown and West 2000; Sims et al. 2008; West et al. 2001). Nevertheless, as long as they exist, individual higher level entities, each instituting their own formal and final causes, harness all lower levels locally into colluding to promote them by way of providing material causes for them from one moment to the next. Individuals continually integrate all of nature into their own embodiment (Polanyi 1968) until they disperse, when they are recycled. As a thought experiment, we might try to imagine a world without particular, history-mediated individual phenomena. We find, I think, that we must go back to something like the primal quark-gluon plasma before this becomes possible. From a 'pansemiotic' perspective (Salthe 2008), the emergence of higher integrative levels can be seen to have pulled the universe into ever more particular meanings.

\section{Conclusion}

This developmental perspective is advanced in order to be posed against the currently fashionable pan-historicism, and yet historicity does play a role. One take-home message would be that if we are to try to anticipate newly emerging events and occasions, we need to develop techniques to assess vague tendencies while they are becoming liminal and beginning to emerge (Salthe 2004). In connection with this, acting on Charles Peirce's (1905) suggestion to develop a 'logic of vagueness', is long overdue.

Acknowledgments I thank Victoria Alexander, Richard Gordon, Igor Matutinovic, John McCrone, John Smart, Clément Vidal, and Michael Zimmerman for stimulating discussions or improving suggestions.

\section{References}

Bonner, J. T. (2006). Why size matters. Princeton: Princeton University Press.

Brooks, D. R., \& Wiley, E. O. (1988). Evolution as entropy: Toward a unified theory of biology (2nd ed.). Chicago: University of Chicago Press. 
Brown, J. H., \& West, G. B. (Eds.). (2000). Scaling in biology. New York: Oxford University Press.

Carnot, S. (1824/1960). Reflections on the motive power of fire and on machines fitted to develop that power. In E. Mendoza (Ed.), Reflections on the motive power of fire and other papers (pp. 3-22). New York: Dover.

Chaisson, E. J. (2001). Cosmic evolution: The rise of complexity in nature. Cambridge, MA: Harvard University Press.

Damuth, J. (1985). Selection among species: A reformulation in terms of natural functional units. Evolution, 39, 1132-1146.

Einstein, A. (1907/1989). On the relativity principle and the conclusions to be drawn from it. In The collected papers of Albert Einstein, Vol. 2: The Swiss Years: Writings, 1900-1909. Princeton University Press, Princeton. (Translated by Anna Beck).

Elsasser, W. M. (1969). Acausal phenomena in physics and biology: A case for reconstruction. American Scientist, 57, 502-516.

Esposito, J. L. (1977). Schelling's idealism and philosophy of nature. Lewisburg: Bucknell University Press.

Ewens, W. J. (2004). Mathematical population genetics: Theoretical introduction. New York: Springer.

Goodman, N. (1976). Languages of art: An approach to a theory of symbols. Indianapolis, IN: Hackett.

Greenberg, G., \& Tobach, E. (Eds.). (1988). Evolution of social behavior and integrative levels. Hillsdale, NJ: Lawrence Erlbaum.

Holling, C. S. (1986). The resilience of terrestrial ecosystems. In W.C. Clark \& R.E. Munn (Eds.), Sustainable development of the biosphere (pp. 292-320). Cambridge, UK: Cambridge University Press.

Lineweaver, C. H., \& Egan, C. A. (2008). Life, gravity and the second law of thermodynamics. Physics of Life Reviews, 5, 225-242.

Matthen, M. (1989). The four causes in Aristotle's embryology. In: R. Kraut \& T. Penner (Eds.) Nature, knowledge and virtue. Apeiron: Special Issue 22.4:159-180.

Neurath, O., Carnap, R., \& Morris, C. (Eds.). (1955-1969). Foundations of the unity of science: Toward an ecyclopedia of unified science. Chicago: University of Chicago Press.

Nicolis, G. (1986). Dynamics of hierarchical systems: An evolutionary approach. Berlin: Springer.

Odum, H. T. (1983). Systems ecology: An introduction pp. 102,116. New York: Wiley Interscience.

Patten, B. C., Bosserman, R. W., Finn, J. T., \& Gale, W. G. (1976). Propagation of cause in ecosystems. In B. C. Patten (Ed.), Systems analysis and simulation in ecology (Vol. 4). New York: Academic Press.

Peirce, C. S. (1905). Issues of pragmatism. The Monist, 15, 481-499.

Peirce, C. S. (1931-1958). Collected papers, Vols. I-VIII. In C. Hartshorne \& P. Weiss (Eds.) Harvard University Press, Cambridge, MA

Polanyi, M. (1968). Life's irreducible structure. Science, 160, 1308-1312.

Poli, R. (1998). Levels. Axiomanthes Nos, 1-2, 197-211.

Popper, K. R. (1990). A world of propensities. Bristol: Thoemmes.

Prigogine, I. (1955). Introduction to thermodynamics of irreversible processes. New York: Wiley Interscience.

Reid, R. G. B. (2007). Biological emergences: Evolution by natural experiment. Cambridge, MA: MIT Press.

Salthe, S. N. (1985). Evolving hierarchical systems: Their structure and representation. New York: Columbia University Press.

Salthe, S. N. (1988). Notes toward a formal history of the levels concept. In G. Greenberg \& E. Tobach (Eds.), Evolution of social behavior and integrative levels. Hillside, N.J: L. Erlbaum Associates.

Salthe, S. N. (1989). Self-organization of/in hierarchically structured systems. Systems Research, 6, 199-208.

Salthe, S. N. (1993). Development and evolution: Complexity and change in biology. Cambridge, MA: MIT Press.

Salthe, S. N. (2000). Translation into and out of language. Athanor X, n.s. No. 2,167-177.

Salthe, S. N. (2002). Summary of the principles of hierarchy theory. General Systems Bulletin, 31, $13-17$.

Salthe, S. N. (2004). The natural philosophy of ecology: developmental systems ecology. Ecological Complexity, 2, 1-19.

Salthe, S. N. (2005). An approach to causality in organized complexity: the role of management. In K. Richardson (Ed.) Managing the Complex: Philosophy, Theory, Practice. I.A.P./I.S.C.E. Managing the Complex Book Series, Vol. 1 (pp. 81-94).

Salthe, S. N. (2006a). On Aristotle's conception of causality. General Systems Bulletin, 35, 11.

Salthe, S. N. (2006b). Two frameworks for complexity generation in biological systems. Evolution of Complexity. ALifeX Proceedings. C. Gershenson \& T. Lenaerts (Eds.). Indiana University Press, Bloomington, IN. http://ecco.vub.be/EDO/Salthe.pdf. 
Salthe, S. N. (2008). The System of Interpretance, Naturalizing Meaning as Finality. Biosemiotics. http:// dx.doi.org/10.1007/s12304-008-9023-3.

Salthe, S. N. (2009). A hierarchical framework for levels of reality: Understanding through representation. Axiomathes, 19, 87-95.

Salthe, S. N., \& Fuhrman, G. (2005). The Cosmic Bellows: The Big Bang and the Second Law. Cosmos and History 1: pp. 295-318. http://www.cosmosandhistory.org.

Schneider, E. D., \& Kay, J. J. (1994). Life as a Manifestation of the Second Law of Thermodynamics. Mathematical and Computer Modelling, 19, 25-48.

Simpson, G. G. (1953). The major features of evolution. New York: Columbia University Press.

Sims, D. W., et al. (2008). Scaling laws of marine predator search behavior. Nature, 451, 1098-1102.

Snowdon, P. (2008). Knowing how and knowing that: A distinction reconsidered. Proceedings of the Aristotelian Society, 104, 1-29.

Turner, J. S. (2000). The extended origanism: The physiology of animal-built structures (p. 31). Cambridge, MA: Harvard University Press.

Turner, M. S. (2007). Quarks and the cosmos. Science, 315, 59-61.

Ulanowicz, R. E. (1997). Ecology, the ascendent perspective. New York: New Columbia University Press.

Ulanowicz, R. E. (2007). Emergence, naturally!. Zygon, 42, 945-969.

Vernadsky, V. I. (1944). Problems of biogeochemistry II. Transactions of the Connecticut Academy of Arts and Sciences, 35, 483-517.

Vernadsky, V. I. (1986). The Biosphere. Synergetic Press, London. (Original work published 1929).

von Uexküll, J. (1926). Theoretical biology. London: Harcourt, Brace.

Weber, A. (1908). History of Philosophy. New York: Charles Scribner's Sons. http://www.uidaho.edu/ Mickelsen/texts/Weber\%20-\%20History/bacon.htm.

West, G. B., Brown, J. H., \& Enquist, B. J. (2001). A general model for ontogenetic growth. Nature, 413, 628-631.

Whitehead, A. N. (1929). Process and reality: An essay in cosmology. New York: Macmillan.

\section{Author Biography}

Stanley N. Salthe graduated with a Ph.D. in Zoology from Columbia University, New York City in 1963. After postdoctoral research in biochemistry at Brandeis University, Waltham, Massachusetts, he began teaching in the Biology Department at Brooklyn College of the City University of New York in 1965, where he remained, teaching evolutionary biology, until his retirement in 1991. His books include Evolutionary Biology, 1972 (Holt, Rinehart \& Winston), Evolving Hierarchical Systems, 1986 (Columbia University Press) and Development and Evolution, 1993 (MIT Press). He has done research and published in biology, systems science, and semiotics. Currently he is engaged in outlining a reinvigorated Natural Philosophy based in a general theory of development. 